\title{
Increased concentrations of platelet- and endothelial-derived microparticles in patients with myocardial infarction and reduced renal function- a descriptive study
}

Josefin Mörtberg ${ }^{1 *}$, Kristina Lundwall², Fariborz Mobarrez ${ }^{3}$, Håkan Wallén $^{2}$, Stefan H. Jacobson ${ }^{1}$ and Jonas Spaak ${ }^{2}$

\begin{abstract}
Background: Patients with chronic kidney disease (CKD) have a high risk of recurring thrombotic events following acute myocardial infarction (AMI). Microparticles (MPs) are circulating small vesicles shed from various cells. Platelet microparticles (PMPs) reflect platelet activation and endothelial microparticles (EMPs) reflect endothelial activation or dysfunction. Both increase following AMI, and may mediate important biological effects. We hypothesized that AMI patients with CKD have further elevated PMPs and EMPs compared with non-CKD patients, despite concurrent antithrombotic treatment.

Methods: We performed a descriptive study of patients with AMI. Fasting blood samples were acquired from 47 patients on dual antiplatelet treatment. Patients were stratified by renal function: normal $(H ; n=19)$ mean eGFR 88; moderate CKD (CKD3; $n=15)$ mean eGFR 47, and severe CKD (CKD4-5; $n=13)$ mean eGFR $20 \mathrm{~mL} / \mathrm{min} / 1.73 \mathrm{~m}^{2}$. MPs were measured by flow-cytometry and phenotyped according to size $(<1.0 \mu \mathrm{m})$ and expression of CD41 (GPIlb; PMPs) and CD62E (E-selectin; EMPs). In addition, expression of platelet activation markers P-selectin (CD62P) and CD40ligand (CD154) were also investigated.

Results: PMPs expressing CD40 ligand were higher in CKD4-5: $210 / \mu \mathrm{l}$ (174-237); median and interquartile range; vs. group $\mathrm{H} ; 101 / \mu \mathrm{l}(71-134 ; p<0.0001)$ and CKD 3: $142 / \mu \mathrm{l}(125-187 ; p=0.006)$. PMPs expressing P-selectin were higher in CKD4-5 compared with $\mathrm{H}$, but not in CKD3. EMPs were higher in CKD4-5; $245 / \mu \mathrm{l}$ (189-308) compared with $\mathrm{H} ; 83 / \mu \mathrm{l}(53-140 ; \mathrm{p}<0.0001)$ and CKD3; $197 / \mu \mathrm{l}(120-245 ; p<0.002)$.

Conclusions: In AMI patients, PMPs and EMPs from activated platelets and endothelial cell are further elevated in CKD patients. This indicate impaired endothelial function and higher platelet activation in CKD patients, despite concurrent antiplatelet treatment.
\end{abstract}

Keywords: Renal dysfunction, Renal failure, Chronic kidney disease, Acute coronary syndrome, Thrombosis, Haemostasis

\section{Background}

Chronic kidney disease (CKD) is a large and growing health problem which affects $10-18 \%$ of the population in the western world $[1,2]$. CKD patients have a markedly increased risk to develop cardiovascular disease (CVD) including acute myocardial infarction (AMI) [3, 4]. They also have an increased risk of mortality and morbidity

\footnotetext{
* Correspondence: josefin.mortberg@sll.se

${ }^{1}$ Division of Nephrology, Department of Clinical Sciences, Danderyd

University Hospital, Karolinska Institutet, Stockholm, Sweden

Full list of author information is available at the end of the article
}

after a cardiovascular event, such as AMI, stroke, and following coronary artery bypass graft surgery [5-7]. This is only partially explained by a high prevalence of traditional Framingham risk factors such as smoking, dyslipidaemia, hypertension, hyperglycaemia and obesity. In CKD, non-traditional risk factors including oxidative stress, inflammation, malnutrition, anaemia, endothelial dysfunction, hyper-homocysteinemia, and abnormal calcium phosphate metabolism have all been shown to contribute $[8,9]$. CKD patients also have a disturbed haemostasis shifted towards a prothrombotic state [10]. At the same

(c) The Author(s). 2019 Open Access This article is distributed under the terms of the Creative Commons Attribution 4.0 International License (http://creativecommons.org/licenses/by/4.0/), which permits unrestricted use, distribution, and 
time as CKD patients have a high risk of thrombotic events, they also have an increased risk of bleeding [11]. This may in part explain why CKD patients are less likely to receive early revascularisation when they have an AMI, and receive less evidence based secondary prevention treatment $[12,13]$.

Microparticles (MPs) are small sized vesicles 0.1$1.0 \mu \mathrm{m}$ circulating in blood under normal physiological conditions. They are shed from various cell types such as platelets, endothelial cells and leucocytes, in particular when cells are activated or during apoptosis. Activation occurs mainly by different chemical stimuli or shear stress. MPs can carry bioactive surface- and intracellular proteins originating from the parent cells.

MPs are described as future biomarkers for various diseases. Recent studies have shown that they also actively induce biological responses and inter-cellular cross-talk [14-16]. MPs may expose phosphatidylserine (PS) on the outer surface, offering a negatively charged surface that promotes coagulation and fibrin formation [17]. They are elevated in several diseases, especially those associated with vascular injury, inflammation and prothrombosis, such as diabetes mellitus, CKD, hypertension, atherosclerosis and following an AMI [18-20].

Platelet derived MPs (PMPs) are the most abundant in the circulation, followed by endothelial derived microparticles (EMPs).

PMPs carry several proteins and cytokines expressed on the surface of platelets, such as integrin glycoprotein (GP) IIb/IIIa (CD41/61), GPIX (CD42a), GPIb (CD42b) as well as platelet activation markers P-selectin (CD62P), and CD40 ligand (CD154). All of which can promote PMPs an ability to recruit inflammatory cells, especially leukocytes and monocytes, induce adhesion to endothelial cells, and influence haemostasis [14, 17]. PMPs appear to have a direct effect on platelet aggregation and haemostasis [21], and have an ability to decrease fibrin network permeability in vitro [22]. Circulating PMP concentrations increase in patients with various diseases such as AMI, diabetes mellitus, hypertension, asymptomatic atherosclerotic lesions, and in CKD [18-20, 23].

Endothelial microparticles (EMPs) are released upon endothelial cell activation or apoptosis, and therefore express activation molecules on their surface, such as E-selectin (CD62E), vascular cell adhesion molecules (VCAM-1) and intercellular adhesion molecules (ICAM-1). Endothelial dysfunction is an early hallmark of atherosclerosis and cardiovascular disease [24]. EMPs correlate with the level of endothelial activation both in CVD and CKD, and a high level of endothelial MP shedding may reflect dysfunction or damage $[23,25,26]$. In line with this there seem to be a correlation between levels of EMPs and risk of cardiovascular events and death [27-30].
Thus, PMPs and EMPs are markers of an activated state, and are shown to be useful biomarkers of atherosclerosis and cardiovascular disease [20]. Growing evidence indicate that their biological effect may contribute to an increased risk of recurring thrombotic events in CKD patients, and might be an important link between endothelial dysfunction and a pro-thrombosis state.

CKD patients have more recurrent thromboembolic events and worse prognosis after an AMI, and current antithrombotic treatments may be less efficacious in these patients. In order to study this, we assessed platelet and endothelial activation by measuring circulating PMPs and EMPs in AMI patients with normal and reduced renal function.

\section{Methods \\ Patients and study design}

In this descriptive study we used plasma samples from the Stockholm heart bank biobank (NCT01204645) including patients donating blood during an AMI. The AMI diagnosis was decided by routine evaluation of clinical history, ECG and Trop I levels. Renal function was estimated using the CKD-EPI formula in $\mathrm{mL} / \mathrm{min} / 1.73 \mathrm{~m}^{2}$. We stratified the patients in the biobank $(n=811)$ according to their renal function: non CKD (H), CKD 3 and CKD 4-5, and then selected 20 patients consecutively from each of the groups. After excluding patients on dialysis, transplanted patients, and patients without treatment with antiplatelet therapy P2Y12 receptor antagonists, 47 patients remained. Patients with normal renal function $(\mathrm{H} ; n=19)$ had a mean eGFR of $88 \mathrm{~mL} / \mathrm{min} / 1.73 \mathrm{~m} 2$; moderate CKD (CKD $3 ; n=15)$ mean eGFR $47 \mathrm{~mL} / \mathrm{min} / 1.73 \mathrm{~m} 2$, and severe CKD (CKD 4-5; $n=13)$ mean eGFR $20 \mathrm{~mL} / \mathrm{min} / 1.73 \mathrm{~m} 2$.

All patient's previous medical records were examined to ensure that the renal function at admission reflected their previous levels, and that they fulfilled the criteria for a chronic kidney disease diagnosis.

The patients were included in the biobank between 2010 and 2015. Analysis were performed in 2016-17. The study was approved by the Ethics committee of the Karolinska Institutet, Stockholm, Sweden. Baseline characteristics are listed in Table 1.

\section{Blood samples}

All samples were acquired fasting in the morning 1-3 days after admission for an AMI. Antecubital venous blood was sampled in test tubes containing 1/10 0.129 $\mathrm{M}$ sodium citrate. Platelet poor plasma (PPP) was collected after centrifugation at $2000 \mathrm{G}$ for $20 \mathrm{~min}$ at room temperature (RT) and then frozen in aliquots at $-80^{\circ} \mathrm{C}$ until analysis. Centrifugation started within $20 \mathrm{~min}$ after the blood was drawn. 
Table 1 Patient characteristics

\begin{tabular}{|c|c|c|c|}
\hline & Normal kidney function $(\mathrm{H})$ & CKD 3 & CDK 4-5 \\
\hline Subjects & $n=19$ & $n=15$ & $n=13$ \\
\hline Mean eGFR (mL/min/1.73m²) & 88 & 47 & 20 \\
\hline Mean Age (years) & 66 & 76 & 74 \\
\hline Sex ratio Female/Male & $31 \% \mathrm{~F}(6 \mathrm{~F} / 13 \mathrm{M})$ & $13 \% \mathrm{~F}(2 \mathrm{~F} / 13 \mathrm{M})$ & $40 \%(5 F / 8 M)$ \\
\hline Smoking & $32 \%(6 / 19)$ & $20 \%(3 / 15)$ & $8 \%(1 / 13)$ \\
\hline Diabetes mellitus 2 & $21 \%(4 / 19)$ & $40 \%(6 / 15)$ & $69 \%(9 / 13)$ \\
\hline STEMI & $47 \%(9 / 19)$ & $47 \%(7 / 15)$ & $46 \%(6 / 13)$ \\
\hline Non-STEMI & $52 \%(10 / 19)$ & $53 \%(8 / 15)$ & $54 \%(7 / 13)$ \\
\hline Angiography before sampling & $89 \%(17 / 19)$ & $85 \%(11 / 15)$ & $77 \%(10 / 13)$ \\
\hline PCI before sampling & $68 \%(13 / 19)$ & $40 \%(6 / 15)$ & $69 \%(9 / 13)$ \\
\hline Angiography after sampling & $5 \%(1 / 19)$ & $20 \%(3 / 15)$ & $15 \%(2 / 13)$ \\
\hline No angiography & $5 \%(1 / 19)$ & $7 \%(1 / 15)$ & $8 \%(1 / 13)$ \\
\hline $\mathrm{PCl}$ anytime & $74 \%(14 / 19)$ & $47 \%(7 / 15)$ & $77 \%(10 / 13)$ \\
\hline Hypertension & $58 \%(11 / 19)$ & $93 \%(14 / 15)$ & $100 \%(13 / 13)$ \\
\hline Chronic ischemic heart disease & $26 \%(5 / 19)$ & $47 \%(7 / 15)$ & $69 \%(9 / 13)$ \\
\hline Sample day & Mean 2.6 & Mean 2.6 & Mean 3.9 \\
\hline \multicolumn{4}{|l|}{ Medications: } \\
\hline Acetylsalicylic acid & $95 \%(18 / 19)$ & $93 \%(14 / 15)$ & $100 \%(13 / 13)$ \\
\hline $\mathrm{P}_{2} \mathrm{Y}_{12}$ receptor antagonists & $100 \%$ & $100 \%$ & $100 \%(13 / 13)$ \\
\hline Clopidogrel & $84 \%(16 / 19)$ & $85 \%(11 / 15)$ & $92 \%(12 / 13)$ \\
\hline Ticagelor & $11 \%(2 / 19)$ & $20 \%(3 / 15)$ & $15 \%(2 / 13)$ \\
\hline Prasugrel & $5 \%(1 / 19)$ & $7 \%(1 / 15)$ & $0 \%(0)$ \\
\hline LMWH & $42 \%(8 / 19)$ & $53 \%(8 / 15)$ & $23 \%(3 / 13)$ \\
\hline Warfarin & 0 & 0 & $8 \%(1 / 13)$ \\
\hline NOAK & 0 & 0 & 0 \\
\hline Statin & $84 \%(16 / 19)$ & $87 \%(13 / 15)$ & $85 \%(11 / 13)$ \\
\hline \multicolumn{4}{|l|}{ Laboratory parameters: } \\
\hline Mean Platelet count $10^{9} / \mathrm{L}$ & $212 \pm 57$ & $188 \pm 54$ & $205 \pm 83$ \\
\hline Mean Leucocyte count $10^{9} / \mathrm{L}$ & $9,0 \pm 2.7$ & $7.6 \pm 1.3$ & $11.5 \pm 5.7$ \\
\hline Mean p-albumin (g/L) & $35 \pm 3$ & $33 \pm 3$ & $30 \pm 7$ \\
\hline Mean p-phosphate (mmol/L) & $1.06 \pm 0.16$ & $1.05 \pm 0.15$ & $1.22 \pm 0.37$ \\
\hline
\end{tabular}

\section{Microparticle analysis}

PPP was later thawed and was initially centrifuged at 2000 $\mathrm{G}$ for $20 \mathrm{~min}$ at RT. The supernatant was centrifuged again at $13000 \mathrm{G}$ for $2 \mathrm{~min}$. Subsequently, $20 \mu \mathrm{l}$ of the supernatant was incubated for $20 \mathrm{~min}$ in dark with lactadherin-FITC (Coatech AB; BLAC-FITC), CD41-APC or PC7 (Beckman Coulter, Brea, CA, USA), CD62P-PE (Thermo Fisher Scientific, Waltham, MA, USA), CD154-APC (Thermo Fisher Scientific, Waltham, MA, USA) and CD62E-APC (Thermo Fisher Scientific, Waltham, MA, USA). MPs were defined as particles less than $1.0 \mu \mathrm{m}$ in size and positive to lactadherin (binds to exposed phosphatidylserine) and cell-markers described above. All samples were analysed using a Beckman Coulter Gallios flow cytometer (Beckman Coulter, Brea, CA, USA), and the MP-gate was calibrated using Megamix beads (FSC; $0.3 \mu \mathrm{m}$, $0.5 \mu \mathrm{m}$ and $0.9 \mu \mathrm{m}$ BioCytex, Marseille, FR). In the present study results are shown as concentrations of MP detected (MPs/ul plasma).

\section{Blood chemistries/routine laboratory markers}

Additional blood samples for routine analysis were obtained and analysed by the clinical chemistry Laboratory of the Karolinska University Hospital, Stockholm, Sweden.

\section{Statistical methods}

Sample size in this descriptive, explorative study was based on a large effect size $(f>0.6)$ shown in previous 
similar studies, requiring at least 12 subjects in each of the three groups. The MP concentrations are presented as medians with upper and lower quartile values in parenthesis. None of the MP variables were normally distributed according to Shapiro-Wilks normality test. Between group differences were tested using the Kruskal-Wallis analysis and post hoc analyses by the Mann Whitney U test. Significance was accepted at $p<0.05$. Regression analyses including MP concentrations, diabetes mellitus and eGFR were performed. Statistical analyses were performed using SPSS software, version 22 (SPSS Inc., Chicago, IL, USA).

\section{Results}

Forty-seven patients were included in the study, and patient's characteristics are summarized in Table 1 . As can be seen, the group with normal renal function was younger and had less comorbidities, such as diabetes mellitus and hypertension, compared with the two groups with renal failure. The medical treatment was similar in the three groups. All patients were treated with antiplatelet therapy $\mathrm{P}_{2} \mathrm{Y}_{12}$ receptor antagonists (mainly clopidogrel; see Table I), and all but two patients were on ASA therapy. Ongoing statin treatment was the same in all groups.

Table 2 and Fig. 1a-c and 2 show concentrations of MPs in the three groups. Figure 3a-c and 4 show scatterplots illustrating the correlation between eGFR and the MP concentrations in patients with and without diabetes mellitus diagnosis. The regression analyses showed correlations between eGFR and MP concentration, both in patients with and without diabetes mellitus.

Three-group comparisons using Kruskal Wallis method showed significant increases in CKD groups for the total concentrations of PMPs (CD41), for PMPs expressing platelet activation marker CD40 ligand (CD154) and
P-selectin (CD62P) as well as EMPs expressing endothelial activation marker E-selectin (CD62E).

Post hoc analyses with two group comparisons were performed with Mann-Whitney $U$ test, and showed that concentrations of PMPs expressing platelet activation marker CD40 ligand differed significantly between all three groups of patients with AMI. The concentration was highest in CKD 4-5; 210 (174-237; median and interquartile range), elevated in CKD 3; 142 (125-187) and lowest in the group with normal renal function, group H; 101 (71-134).

P-selectin positive PMPs were higher in the AMI group with CKD 4-5; 253 (227-461; $p<0.000)$, compared with $\mathrm{H} ; 106$ (79-158). We found a numerical trend towards higher P-selectin PMPs in CKD 3; 147 (111-174), compared with H; 106 (79-158), but this was not significant $(p=0.11)$.

Total concentrations of PMPs differed significantly between group H; 424 (328-534) and CKD 4-5; 1576 (666-2351; $p=0.002)$. Between group $\mathrm{H}$ and group CKD 3 ; 600 (401-888), the numerical differences observed when comparing the median concentrations of PMPs was not significant $(p=0.19)$.

Concentrations of CD62E positive (E-selectin) EMPs were significantly higher in both CKD groups: CKD 4-5; 245 (189-308) compared with H; 83 (53-140; $p<0.0001)$ and CKD 3; 197(120-245) compared with $\mathrm{H}(p<0.002)$. Concentrations of EMPs appeared numerically higher in CKD 4-5 compared with CKD 3, but this was not significant $(p=0.118)$.

Routine laboratory markers showed that platelets and white blood cell counts were the same between the three groups of patients with AMI. Mean plasma albumin levels were 30 and $33 \mathrm{~g} / \mathrm{L}$ in CKD 3 and CKD 4-5 respectively, and $35 \mathrm{~g} / \mathrm{L}$ in $\mathrm{H}$.

Table 2 MP concentrations Median and interquartile range $a=p$ value for comparison between the three groups. $b=p$ value for comparison between the two groups listed

\begin{tabular}{|c|c|c|c|c|}
\hline & $\mathrm{H}$ & CKD 3 & CKD 4-5 & $p$-value ${ }^{a}$ \\
\hline PMP (count/ML) (CD41) & $424(328-534)$ & $600(401-888)$ & $1576(666-2351)$ & $\begin{array}{l}0.001^{\mathbf{a}} \\
(C K D 3 \text { vs CKD 4-5, } \boldsymbol{p}=\mathbf{0 . 0 2 2})^{\mathrm{b}} \\
(\text { CKD3 vs H,p }=0.186)^{\mathrm{b}} \\
(\text { CKD4-5 vs H, } \boldsymbol{p}=\mathbf{0 . 0 0 2})^{b}\end{array}$ \\
\hline P-selectin positive PMP (count/ $\mu \mathrm{L}$ ) (CD 62P) & $106(79-158)$ & $147(111-174)$ & $253(227-461)$ & 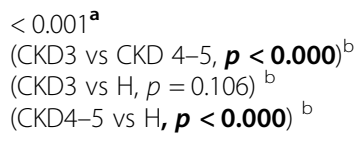 \\
\hline CD40 ligand positive PMP (count/ML) (CD154) & $101(71-134)$ & $142(125-187)$ & $210(174-237)$ & $\begin{array}{l}<0.001^{\mathbf{a}} \\
(C K D 3 \text { vs CKD 4-5, } \boldsymbol{p}<\mathbf{0 . 0 0 3})^{\mathrm{b}} \\
(\mathrm{CKD} 3 \text { vs H, } \boldsymbol{p}=\mathbf{0 . 0 0 6})^{\mathrm{b}} \\
(\mathrm{CKD} 4-5 \text { vs H, } \boldsymbol{p}<\mathbf{0 . 0 0 0})^{\mathrm{b}}\end{array}$ \\
\hline E-selectin positive MP (count/ML) (CD 62E) & $83(53-140)$ & $197(120-245)$ & $245(189-308)$ & $\begin{array}{l}<0.001^{\mathbf{a}} \\
(C K D 3 \text { vs CKD } 4-5, p<0.118)^{b} \\
(\text { CKD3 vs H, } \boldsymbol{p}=\mathbf{0 . 0 0 2})^{b} \\
(C K D 4-5 \text { vs H, } \boldsymbol{p}<\mathbf{0 . 0 0 0})^{b}\end{array}$ \\
\hline
\end{tabular}



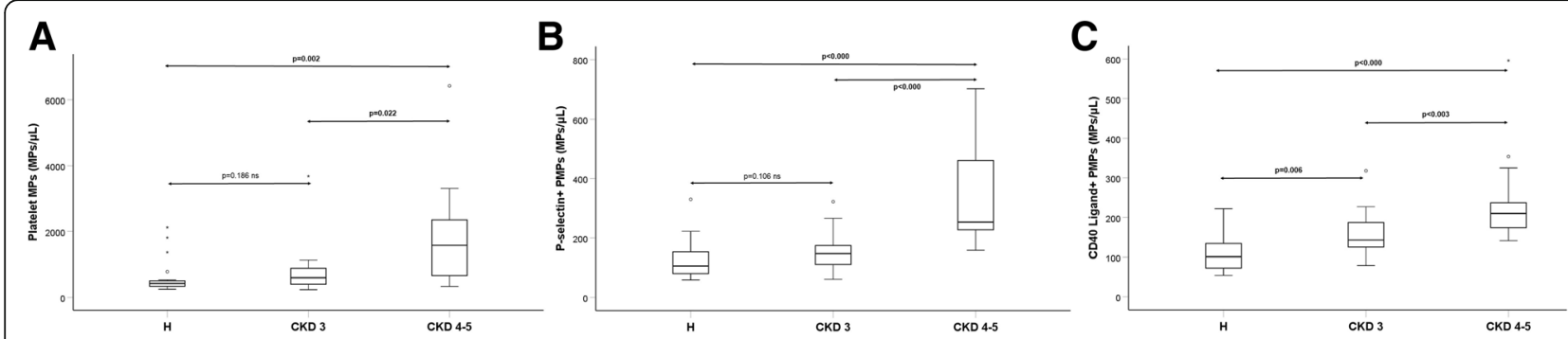

Fig. 1 a-c Box plots of PMP concentrations for the three groups of patients with various degree of kidney function. Group $\mathrm{H}(n=19) ; \mathrm{CKD} 3(n=15)$; CKD 4-5 $(n=13)$

\section{Discussion}

In this descriptive, explorative study, we measured circulating PMPs expressing platelet activation markers CD40 ligand (CD154) and P-selectin (CD62P), as well as levels of EMPs expressing E-selectin (CD62E), in patients who were hospitalized for an AMI and on dual antiplatelet treatment. The patients were divided in three groups according to renal function, and we found that the concentrations of PMPs expressing CD40ligand, and P-selectin, as well as EMPs expressing E-selectin, were significantly higher in patients with severe CKD. Our results are in agreement with the notion that MPs might be a novel pathway that contributes to the poor outcome after a cardiovascular event seen in CKD,

The possible link between MPs and inflammation, vascular dysfunction and pro-thrombosis, were demonstrated in an in vitro study, where PMP enriched blood were able to increase deposition of platelets and fibrin in human atherosclerotic vessels, PMPs hereby directly contributing to thrombosis formation [21].

In AMI, the thrombus formation at the site of injury is dependent on complex interactions between activated platelets, circulating PMPs, activated endothelial cells and the coagulation system [14]. In previous studies it has been shown that AMI patients have high levels of PMPs as well as EMPs [18, 31, 32]. In contrast, one study of ST-elevation AMI patients (STEMI) without CKD showed that PMP concentrations were not significantly different compared to healthy individuals, and the concentrations of PMPs were not associated to outcome [33]. However, in two other studies, high concentrations of both PMPs and EMPs were associated with the severity of AMI $[34,35]$ in non CKD patients. Another recent study in post-AMI patients found that elevated concentrations of P-selectin positive PMPs were associated with an increased risk for a new cardiovascular event [36]. There are currently no outcome studies published on PMPs in AMI patients with reduced renal function, but our results indicate that PMPs may be of particular interest in this patient group.

In our study the concentrations of PMPs expressing activation marker p-selectin as well as PMPs without any activation marker, were higher in the severe kidney disease group CKD 4-5, but not in the moderate kidney disease group CKD 3, compared with the group $\mathrm{H}$ without kidney disease. The reason for this might be simply a to small sample to discover true differences, or this finding might be partially explained by results found in a

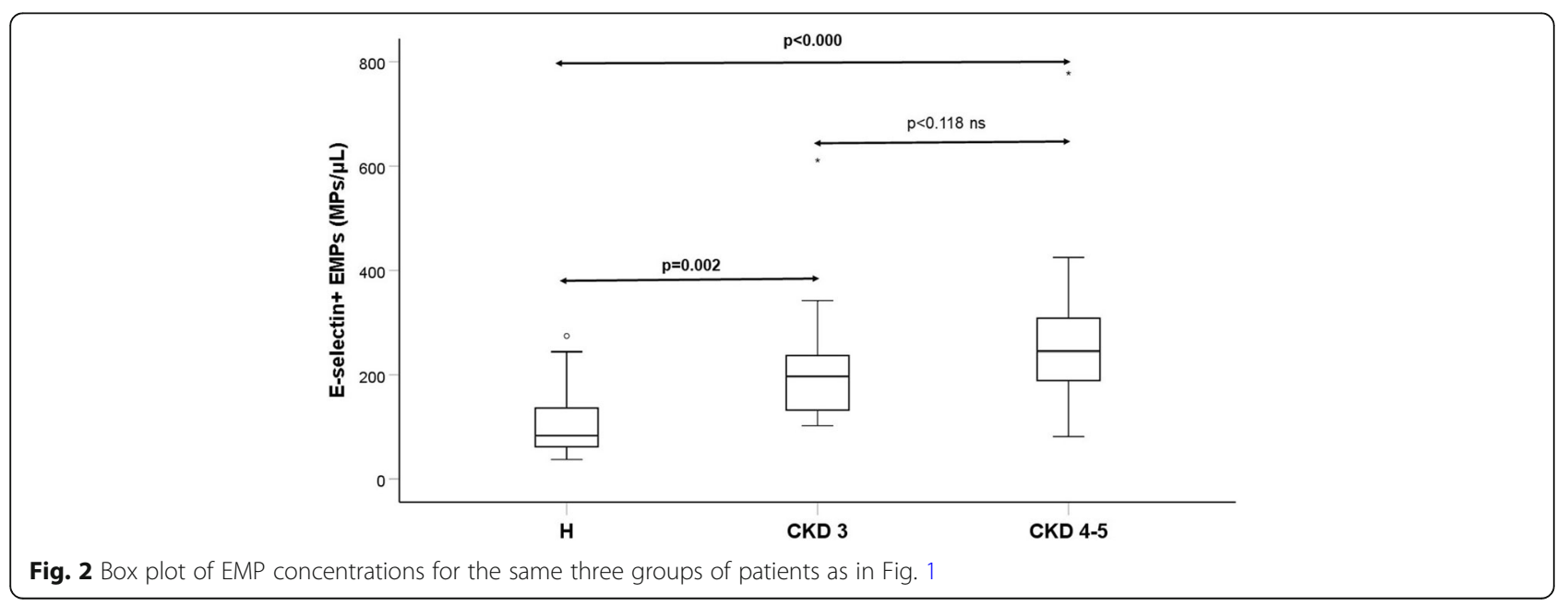



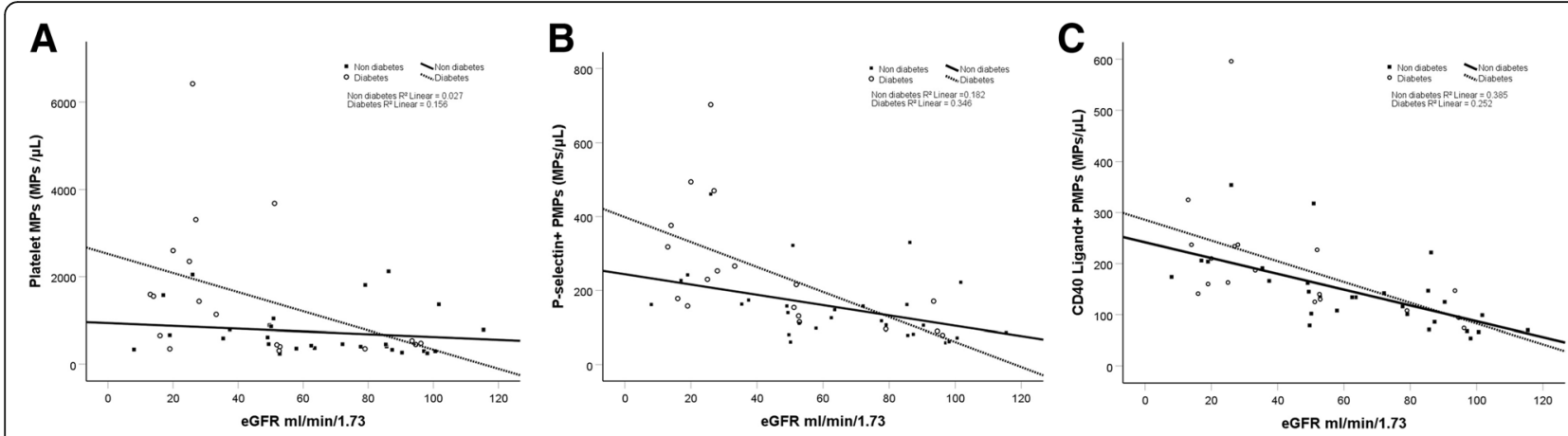

Fig. 3 a-c Scatterplots of concentrations of all PMPs and eGFR. The regression lines shown are stratified for diabetes mellitus (DM) or not

study of platelet reactivity. In this study of high post-treatment platelet reactivity (HPPR), patients with diabetes mellitus and CKD, treated with standard dual antiplatelet treatment, remaining high platelet reactivity was noticed only in severe CKD, not in moderate CDK. The authors speculate that there might exist a threshold after which renal dysfunction impact platelet reactivity [37].

Endothelial dysfunction is evident early in the atherosclerotic process and promotes chronic vascular inflammation commonly seen in CKD [38]. Loss of endothelium dependent vasodilatation is one important factor contributing to functional stiffening of the arteries and subsequent accelerated CVD and progression of CKD [39, 40]. Studies performed have shown a correlation between levels of EMPs and measures of endothelial function [26] and EMPs seem to be chronically high in CKD patients $[15,16,23,41]$. However, there are as far as we know no study performed investigating the levels of EMPs post AMI comparing CKD to non CKD patients. Our results, with higher levels of EMPs in CKD patients post AMI, indicate a more advanced endothelial damage in these

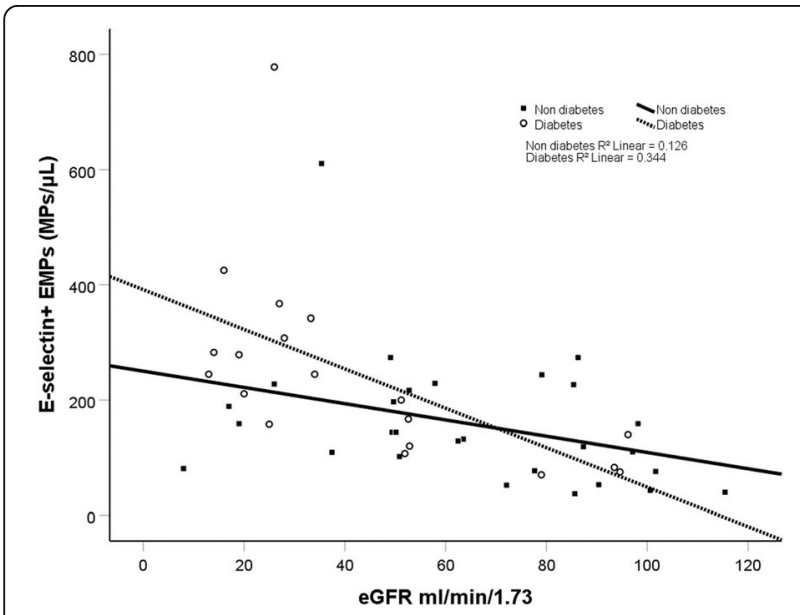

Fig. 4 Scatterplot of concentration of E-selectin positive EMPs in relation to eGFR. The regression lines shown are stratified for diabetes mellitus (DM) or not patients. Further studies with a prospective design are needed to evaluate EMPs role as a prognostic marker in this patient population.

Researchers from our group have previously shown that patients with non STEMI treated with aspirin or statin at admission did not differ in levels of PMPs compared to patients without treatment who were given a bolus of aspirin in the ambulance before admission [31]. However other studies have shown decreasing levels of PMPs after the initiation of antithrombotic treatment [32]. Initiation of statin treatment has also been shown to lower levels of PMPs expressing P-selectin [22, 42] as well as CD40 ligand PMPs [43]. It is therefore important to note that all patients in our study had received the same potent platelet inhibition with P2Y12 antagonists (clopidogrel, ticagrelor or prasugrel) and ASA, latest the day before the blood sampling, and that statin treatment was the same in the three groups. Levels of platelet count were also the same in the groups. Thus, the differences found in the present study were likely not due to different statin or antiplatelet treatment, but may indicate a reduced efficacy of P2Y12 receptor antagonists in CKD patients.

Age, smoking habits and gender differed between the three groups in this study, but the numbers where too few to perform a regression analysis. Previous work, however, have shown that none of these affect the concentrations of MPs in AMI patients without CKD [36]. In our study, hypertension was more common in CKD patients. Previous work has shown that concentrations of EMP and PMP are elevated in severe hypertension, but it is not known whether controlled hypertension, as in our patients, affect concentrations [44].

There was a difference in the proportion of prevalence of diabetes mellitus between the three groups with different eGFR. After adjusting for eGFR and diabetes mellitus, the between group MP differences remained.

Blood samples were taken 1-3 days after the admission for AMI, in the morning, fasting, which reduces diurnal variability. It has previously been shown that PMPs 
decrease $24 \mathrm{~h}$ after initiating ACS treatment, and further decrease after 6 months [31]. According to this there might be a gradual decrease of PMPs as day passes. At the same time, it is known that the delay in AMI patients before they seek acute care vary from hours to days, making it hard to determine the actual time of plaque rupture [45]. In our study, the severe kidney disease group CKD 4-5 had the highest PMPs, despite the fact that their samples were taken almost 1 day later compared with the other groups, supporting the notion that sample delay was not the cause of our findings. The variability $1-3$ days, of which the samples were taken adds an uncertainty to our results, however as discussed above we argue that this variability does not explain our findings.

It is of importance to note that there was no difference in proportion of STEMI versus non STEMI in our three groups since previous papers reported that MP levels vary with type of AMI and infarction size [34, 35]. There were some differences in the proportion of patients undergoing percutaneous coronary intervention (PCI), with slightly fewer PCIs in the group with CKD 3. There are conflicting results regarding the effect on MP levels after PCI. Two studies [46, 47] that collected blood from the culprit lesion, show initially increased MPs, decreasing after PCI, interpreted as due to the initiation of antiplatelet treatment and the restored blood flow. Another study found decreased levels of PMPs, but augmented levels of EMPs, reflecting the acute endothelial injury after PCI [32]. Our results might be affected by these findings, since CKD group 3 had slightly less PCIs performed. Even so the differences were clearest between the control group and the group with CKD stage 4-5, which indicates that our results are not explained only due to PCI or not.

These findings all together indicates that a prospective outcome study with a larger sample size would be warranted.

\section{Limitations of the study}

The main limitation of this explorative study is the small number of patients with a limited power to exclude smaller differences between the group, and limited power to adjust for potential confounders as discussed above. A second limitation is the lack of a control group without myocardial infarction.

\section{Conclusions}

In patients with AMI, concentrations of PMPs expressing platelet activation markers CD40 ligand (CD154) and P-selectin (CD62P), as well as EMPs expressing markers of endothelial activation E-selectin (CD62E) were significantly higher in patients with severe CKD, compared with CKD 3 and normal kidney function patients, when adjusting for diabetes mellitus prevalence. This indicates further impaired endothelial function and higher platelet activation in CKD patients, despite concurrent dual antiplatelet and statin treatment. Our results highlight the need for further studies on antiplatelet treatment and efficacy in CKD patients, and the potential role of MPs as prognostic markers.

\section{Abbreviations \\ AMI: Acute myocardial infarction; CKD 3: Chronic kidney disease stage 3; CKD 4-5: Chronic kidney disease stage 4 and 5; CVD: Cardiovascular disease; eGFR: Estimated glomerular filtration; EMPs: Endothelial microparticles; MP: Microparticles; PMPs: Platelet microparticles; PPP: Platelet poor plasma; ACS: acute coronary syndrome}

\section{Acknowledgements}

We would like to thank Katherina Aguilera-Gatica for performing the Flow cytometry analysis, and Fredrik Johansson for support with the statistical analysis.

\section{Funding}

No external funding.

\section{Availability of data and materials}

All original and supporting data is stored at the department in accordance with the General Data Protection Regulation and may be provided upon request.

\section{Authors' contributions}

All authors JM, KL, FM, HW, SJ and JS participated in the design and planning of the study. JM and JS selected the patients. The flow cytometry analysis was carried out by the staff in the lab. FM analysed the microparticle results. JM and the statistician at the department performed the statistical analysis. All listed authors JM, KL, FM, HW, SJ and JS participated in all interpretation of data and writing of the manuscript. All authors JM, KL, FM, HW, SJ and JS read and approved the final manuscript.

\section{Ethics approval and consent to participate}

The Regional Ethics committee of Stockholm, Sweden, approved the study Dnr 2017/759-31. Verbal and written informed consent was obtained from all participants in the study.

\section{Consent for publication}

Not applicable.

\section{Competing interests}

The authors declare that they have no competing interests. The results presented in this paper have not been published previously in whole or part, except in abstract format. None of the contribution authors have any conflict of interests do declare pertinent the present paper.

\section{Publisher's Note}

Springer Nature remains neutral with regard to jurisdictional claims in published maps and institutional affiliations.

\section{Author details}

${ }^{1}$ Division of Nephrology, Department of Clinical Sciences, Danderyd University Hospital, Karolinska Institutet, Stockholm, Sweden. ${ }^{2}$ Division of Cardiovascular Medicine, Department of Clinical Sciences, Danderyd University Hospital, Karolinska Institutet, Stockholm, Sweden. ${ }^{3}$ Rheumatology Unit, Department of Medicine, Solna, Karolinska Institutet, Karolinska University Hospital, Stockholm, Sweden.

Received: 29 May 2018 Accepted: 19 February 2019

Published online: 01 March 2019

\section{References}

1. Coresh J, Selvin E, Stevens LA, Manzi J, Kusek JW, Eggers P, et al. Prevalence of chronic kidney disease in the United States. Jama. 2007;298(17):2038-47. 
2. Coresh J. Update on the burden of CKD. J Am Soc Nephrol. 2017;28(4): $1020-2$.

3. Go AS, Chertow GM, Fan D, McCulloch CE, Hsu CY. Chronic kidney disease and the risks of death, cardiovascular events, and hospitalization. N Engl J Med. 2004;351(13):1296-305.

4. Tonelli M, Muntner P, Lloyd A, Manns BJ, Klarenbach S, Pannu N, et al. Risk of coronary events in people with chronic kidney disease compared with those with diabetes: a population-level cohort study. Lancet (London, England). 2012;380(9844):807-14.

5. Anavekar NS, McMurray JJ, Velazquez EJ, Solomon SD, Kober L, Rouleau JL, et al. Relation between renal dysfunction and cardiovascular outcomes after myocardial infarction. N Engl J Med. 2004;351(13):1285-95.

6. Yahalom G, Schwartz R, Schwammenthal Y, Merzeliak O, Toashi M, Orion D, et al. Chronic kidney disease and clinical outcome in patients with acute stroke. Stroke. 2009:40(4):1296-303.

7. Holzmann M, Jernberg T, Szummer K, Sartipy U. Long-term cardiovascular outcomes in patients with chronic kidney disease undergoing coronary artery bypass graft surgery for acute coronary syndromes. J Am Heart Assoc. 2014;3(2):e000707.

8. Stenvinkel P, Carrero JJ, Axelsson J, Lindholm B, Heimburger O, Massy Z. Emerging biomarkers for evaluating cardiovascular risk in the chronic kidney disease patient: how do new pieces fit into the uremic puzzle? Clin J Am Soc Nephrol. 2008:3(2):505-21.

9. Zewinger S, Schumann T, Fliser D, Speer T. Innate immunity in CKDassociated vascular diseases. Nephrol Dial Transplant. 2016:31(11):1813-21.

10. Mortberg J, Blomback M, Wallen A, He S, Jacobson SH, Spaak J. Increased fibrin formation and impaired fibrinolytic capacity in severe chronic kidney disease. Blood Coagul Fibrinolysis. 2016;27(4):401-7.

11. Manzano-Fernandez S, Marin F, Pastor-Perez FJ, Caro C, Cambronero F, Lacunza J, et al. Impact of chronic kidney disease on major bleeding complications and mortality in patients with indication for oral anticoagulation undergoing coronary stenting. Chest. 2009;135(4):983-90.

12. Fox CS, Muntner P, Chen AY, Alexander KP, Roe MT, Cannon CP, et al. Use of evidence-based therapies in short-term outcomes of ST-segment elevation myocardial infarction and non-ST-segment elevation myocardial infarction in patients with chronic kidney disease: a report from the National Cardiovascular Data Acute Coronary Treatment and intervention outcomes network registry. Circulation. 2010;121(3):357-65.

13. Khedri M, Szummer K, Carrero JJ, Jernberg T, Evans M, Jacobson SH, et al. Systematic underutilisation of secondary preventive drugs in patients with acute coronary syndrome and reduced renal function. Eur J Prev Cardiol. 2017;24(7):724-34.

14. Badimon L, Suades R, Fuentes E, Palomo I, Padro T. Role of platelet-derived microvesicles as crosstalk mediators in Atherothrombosis and future pharmacology targets: a link between inflammation, atherosclerosis, and thrombosis. Front Pharmacol. 2016;7:293.

15. Burger D, Schock S, Thompson CS, Montezano AC, Hakim AM, Touyz RM. Microparticles: biomarkers and beyond. Clin Sci (Lond). 2013;124(7):423-41.

16. Erdbrugger $\mathrm{U}$, Le TH. Extracellular vesicles in renal diseases: more than novel biomarkers? J Am Soc Nephrol. 2016;27(1):12-26.

17. Sinauridze El, Kireev DA, Popenko NY, Pichugin AV, Panteleev MA, Krymskaya OV, et al. Platelet microparticle membranes have 50- to 100-fold higher specific procoagulant activity than activated platelets. Thromb Haemost. 2007;97(3):425-34.

18. Han WQ, Chang FJ, Wang QR, Pan JQ. Microparticles from patients with the acute coronary syndrome impair vasodilatation by inhibiting the Akt/eNOSHsp90 signaling pathway. Cardiology. 2015;132(4):252-60.

19. Nomura S. Microparticle and Atherothrombotic diseases. J Atheroscler Thromb. 2016;23(1):1-9.

20. Boulanger CM, Loyer X, Rautou PE, Amabile N. Extracellular vesicles in coronary artery disease. Nat Rev Cardiol. 2017;14(5):259-72.

21. Suades R, Padro T, Vilahur G, Badimon L. Circulating and platelet-derived microparticles in human blood enhance thrombosis on atherosclerotic plaques. Thromb Haemost. 2012;108(6):1208-19.

22. Tehrani S, Mobarrez F, Antovic A, Santesson P, Lins PE, Adamson U, et al. Atorvastatin has antithrombotic effects in patients with type 1 diabetes and dyslipidemia. Thromb Res. 2010;126(3):e225-31.

23. Trappenburg MC, van Schilfgaarde M, Frerichs FC, Spronk HM, ten Cate H, de Fijter CW, et al. Chronic renal failure is accompanied by endothelial activation and a large increase in microparticle numbers with reduced procoagulant capacity. Nephrol Dial Transplant. 2012;27(4):1446-53.
24. Daiber A, Steven S, Weber A, Shuvaev W, Muzykantov VR, Laher I, et al. Targeting vascular (endothelial) dysfunction. Br J Pharmacol. 2017;174(12): 1591-619.

25. Paudel KR, Panth N, Kim DW. Circulating endothelial microparticles: a key Hallmark of atherosclerosis progression. Scientifica. 2016;2016:8514056.

26. Amabile N, Guerin AP, Leroyer A, Mallat Z, Nguyen C, Boddaert J, et al. Circulating endothelial microparticles are associated with vascular dysfunction in patients with end-stage renal failure. J Am Soc Nephrol. 2005;16(11):3381-8.

27. Nozaki T, Sugiyama S, Sugamura K, Ohba K, Matsuzawa Y, Konishi M, et al. Prognostic value of endothelial microparticles in patients with heart failure. Eur J Heart Fail. 2010;12(11):1223-8.

28. Amabile N, Guerin AP, Tedgui A, Boulanger CM, London GM. Predictive value of circulating endothelial microparticles for cardiovascular mortality in end-stage renal failure: a pilot study. Nephrol Dial Transplant. 2012;27(5): 1873-80.

29. Sinning JM, Losch J, Walenta K, Bohm M, Nickenig G, Werner N. Circulating CD31+/Annexin V+ microparticles correlate with cardiovascular outcomes. Eur Heart J. 2011;32(16):2034-41.

30. Berezin A, Zulli A, Kerrigan S, Petrovic D, Kruzliak P. Predictive role of circulating endothelial-derived microparticles in cardiovascular diseases. Clin Biochem. 2015;48(9):562-8

31. Skeppholm M, Mobarrez F, Malmqvist K, Wallen H. Platelet-derived microparticles during and after acute coronary syndrome. Thromb Haemost. 2012;107(6):1122-9.

32. Ye S, Shan XF, Han WQ, Zhang QR, Gao J, Jin AP, et al. Microparticles from patients undergoing percutaneous coronary intervention impair vasodilatation by uncoupling endothelial nitric oxide synthase. Shock (Augusta, Ga). 2017;48(2):201-208.

33. Giannopoulos G, Oudatzis G, Paterakis G, Synetos A, Tampaki E, Bouras G, et al. Red blood cell and platelet microparticles in myocardial infarction patients treated with primary angioplasty. Int J Cardiol. 2014;176(1):145-50.

34. Chiva-Blanch G, Laake K, Myhre P, Bratseth V, Arnesen H, Solheim S, et al. Platelet-, monocyte-derived and tissue factor-carrying circulating microparticles are related to acute myocardial infarction severity. PLoS One. 2017:12(2):e0172558.

35. Jung C, Sorensson P, Saleh N, Arheden H, Ryden L, Pernow J. Circulating endothelial and platelet derived microparticles reflect the size of myocardium at risk in patients with ST-elevation myocardial infarction. Atherosclerosis. 2012;221(1):226-31.

36. Christersson C, Thulin A, Siegbahn A. Microparticles during long-term follow-up after acute myocardial infarction. Association to atherosclerotic burden and risk of cardiovascular events. Thromb Haemost. 2017;117(8): 1571-81.

37. Angiolillo DJ, Bernardo E, Capodanno D, Vivas D, Sabate M, Ferreiro IL, et al. Impact of chronic kidney disease on platelet function profiles in diabetes mellitus patients with coronary artery disease taking dual antiplatelet therapy. J Am Coll Cardiol. 2010;55(11):1139-46.

38. Stam F, van Guldener C, Becker A, Dekker JM, Heine RJ, Bouter LM, et al. Endothelial dysfunction contributes to renal function-associated cardiovascular mortality in a population with mild renal insufficiency: the Hoorn study. J Am Soc Nephrol. 2006;17(2):537-45.

39. Chen NC, Hsu CY, Chen CL. The strategy to prevent and regress the vascular calcification in Dialysis patients. Biomed Res Int. 2017;2017:9035193.

40. Palombo C, Kozakova M. Arterial stiffness, atherosclerosis and cardiovascular risk: pathophysiologic mechanisms and emerging clinical indications. Vasc Pharmacol. 2016;77:1-7.

41. Soriano S, Carmona A, Trivino F, Rodriguez M, Alvarez-Benito M, Martin-Malo $A$, et al. Endothelial damage and vascular calcification in patients with chronic kidney disease. Am J Physiol Renal Physiol. 2014;307(11):F1302-11.

42. Mobarrez F, He S, Broijersen A, Wiklund B, Antovic A, Antovic J, et al. Atorvastatin reduces thrombin generation and expression of tissue factor, $\mathrm{P}$ selectin and GPIIla on platelet-derived microparticles in patients with peripheral arterial occlusive disease. Thromb Haemost. 2011;106(2):344-52.

43. Almquist T, Mobarrez F, Jacobson SH, Wallen H, Hjemdahl P. Effects of lipidlowering treatment on circulating microparticles in patients with diabetes mellitus and chronic kidney disease. Nephrol Dial Transplant. 2016;31(6): 944-52.

44. Preston RA, Jy W, Jimenez JJ, Mauro LM, Horstman LL, Valle M, et al. Effects of severe hypertension on endothelial and platelet microparticles. Hypertension (Dallas, Tex : 1979) 2003;41(2):211-217. 
45. Leslie WS, Urie A, Hooper J, Morrison CE. Delay in calling for help during myocardial infarction: reasons for the delay and subsequent pattern of accessing care. Heart. 2000;84(2):137-41.

46. Morel O, Pereira B, Averous G, Faure A, Jesel L, Germain P, et al. Increased levels of procoagulant tissue factor-bearing microparticles within the occluded coronary artery of patients with ST-segment elevation myocardial infarction: role of endothelial damage and leukocyte activation. Atherosclerosis. 2009;204(2):636-41.

47. Min PK, Kim JY, Chung KH, Lee BK, Cho M, Lee DL, et al. Local increase in microparticles from the aspirate of culprit coronary arteries in patients with ST-segment elevation myocardial infarction. Atherosclerosis. 2013;227(2): 323-8.

Ready to submit your research? Choose BMC and benefit from:

- fast, convenient online submission

- thorough peer review by experienced researchers in your field

- rapid publication on acceptance

- support for research data, including large and complex data types

- gold Open Access which fosters wider collaboration and increased citations

- maximum visibility for your research: over $100 \mathrm{M}$ website views per year

At $B M C$, research is always in progress.

Learn more biomedcentral.com/submissions 